\title{
Toward Wearable App Design for Children's In-the-World Science Inquiry
}

\author{
Sharon Lynn Chu \\ Texas A\&M University \\ The StoryLab \\ sharilyn@tamu.edu
}

\author{
Brittany Garcia \\ Texas A\&M University \\ The StoryLab \\ brinni@tamu.edu
}

\begin{abstract}
Little is understood on how to design wearables for education, especially for children. We explore how smartwatches may allow children to see the world through the lens of science. In our study, 20 children are tasked to record stories related to specific scientific concepts in their daily life and drawing from their embodied experiences using a commodity smartwatch. Our findings describe the types of 'science stories' that the children capture through the smartwatch, and how the stories relate to science. From our findings, we elicit seven areas of future research needed to catalyze the design of wearable apps to support informal science learning for children.
\end{abstract}

\section{Author Keywords}

Wearables; Children; Science learning; Smartwatch; Storytelling; Narrative.

\section{ACM Classification Keywords}

H.5.m. Information interfaces and presentation (e.g., $\mathrm{HCI}$ ): Miscellaneous.

\section{INTRODUCTION}

The problem of poor college graduation rates from STEM majors and low percentages of 'ready' students entering STEM degrees is well-documented [1]. This is often because students are psychologically disengaged from the process of learning in STEM subjects. According to many models of academic motivation, such as Jones' MUSIC model [2], usefulness is a key factor for student success in science that is difficult for educators to address. Usefulness refers to how students perceive how what they are learning is useful to them and to their future. In science, a lack of perceived usefulness often comes from a lack of personal or cultural relevance of the content to be learned to the student; the science is decontextualized with respect to actual contexts of use [3]; and students are only passive recipients of science content.

Permission to make digital or hard copies of all or part of this work for personal or classroom use is granted without fee provided that copies are not made or distributed for profit or commercial advantage and that copies bear this notice and the full citation on the first page. Copyrights for components of this work owned by others than ACM must be honored. Abstracting with credit is permitted. To copy otherwise, or republish, to post on servers or to redistribute to lists, requires prior specific permission and/or a fee. Request permissions from Permissions@acm.org.

TEI '17, March 20-23, 2017, Yokohama, Japan

(C) 2017 ACM. ISBN 978-1-4503-4676-4/17/03 ...\$15.00

DOI: http://dx.doi.org/10.1145/3024969.3025008
Yet, the child's experiences in the world outside the classroom is rich and full of experiences that implicitly or explicitly relate to science $[4,5]$. This paper is positioned in the tradition of research looking at how 'out-of-school experiences' or 'everyday experiences' may help children to understand and learn about science. While much research in HCI and educational technologies have looked at how to design technologies to support such informal science learning for children, the introduction of wearable technologies presents a new opportunity to fulfill this research goal with an approach that is perhaps more interactive, mobile and immediate for students. Little is understood currently on the potential of wearables to support science learning.

Our work posits that wearables may provide a 'technological lens' by which children may view their world through science. In this paper, we present a study that explored how children make use of smartwatches as a means to record science episodes in their daily life in the form of stories. Rather than showing the effectiveness of a particular approach, the primary objective of our study was to describe and interpret first the type of science-based observations or stories that children derive from their embodied 'in-the-world' experiences, and second the children's experience using a smartwatch as a tool for science learning. Based on our findings, we advance areas where research is needed to move forward the broader agenda of how wearables may support children's informal science learning and inquiry.

Our research addresses elementary school-aged children in the $3^{\text {rd }}$ to $5^{\text {th }}$ grade ( 8 to 11 years old). A major rationale for this target population is that especially in STEM fields, early motivation is critical: "research clearly shows that early childhood experiences serve as a major influence on academic interest ... [and] lead to a positive commitment toward science that is enduring." [6].

In the rest of this paper, we first present the context and motivation for our work, followed by related work on science learning through wearables. We then describe our theoretical foundation in embodied narrative-based learning, and our study with 20 children, before presenting our findings. Finally, we discuss various areas for future research on wearables for science learning.

\section{CONTEXT AND MOTIVATION}

The motivation for our research is two-fold: one track arises from the problems of children gaining a proper understanding of science in the classroom, and the promise of informal 
science education; and the second track is shaped by the lack of research in how wearables may be used to support children's learning and development.

\section{Informal Science Learning}

Learning science entails understanding real-world concepts that address the physical, material and social environment around us. Creating a connection between the outside world in instruction that is situated in a classroom however is challenging. Much literature attempt to tackle this problem. Bouillon and Gomez [7] for example report that "schools are in communities but often not of communities". They further argue that the disconnect in classroom-based instruction may lead to students perceiving learning at school as distinct from learning about life and how to function in everyday settings. This has been referred to as a failure in the enculturation of students into the science way of thinking [4]. Informal science education, sometimes called "casual learning, extended learning, or free-choice learning" [8] has been posited as providing approaches to address such scientific enculturation. Although we do not present a comprehensive review of science enculturation in informal learning here, it has been studied in contexts such as the home (e.g., [9]), field trips (e.g., [10], or summer camps (e.g., [11]). Braund and Reiss [12] for example proposed an evolutionary model of learning that attempts to integrate "more sites of valid data gathering and knowledge production" (museums, science centers, zoos, etc.) beyond the school science laboratory.

We are particularly interested in informal science learning in terms of everyday experiences. In a key report entitled "Learning science in informal environments: People, Places and Pursuits" [13] commissioned by the US National Research Council, the committee reported that while no comprehensive study has been conducted to date, "the sheer number of hours in which individuals encounter scientific information outside school over the life span is far greater than the number of hours of science education in formal classroom environments". The report lays out six strands reflecting the goals and practices of informal science learning: Strand 1 - Experience excitement, interest, and motivation to learn about phenomena in the natural and physical world; Strand 2 - Come to generate, understand, remember, and use concepts, explanations, arguments, models, and facts related to science. Strand 3 - Manipulate, test, explore, predict, question, observe, and make sense of the natural and physical world; Strand 4 - Reflect on science as a way of knowing; on processes, concepts, and institutions of science; and on their own process of learning about phenomena; Strand 5 Participate in scientific activities and learning practices with others, using scientific language and tools; and Strand 6 Think about themselves as science learners and develop an identity as someone who knows about, uses, and sometimes contributes to science.

\section{Wearables for Learning}

Advances in miniaturization, processing power, sensing and battery life have led wearable computing to be commercializable as useful products [14]. Wearables present an opportunity to look at informal science learning from a perspective that is anchored in children's everyday life. Barfield and Caudell [15] define a wearable as a "fully functional, selfpowered, self-contained computer that is worn on the body ... (and) provides access to information, and interaction with information, anywhere and at anytime". Wearables typically possess three main capabilities: sensing (observing physical environments); analysis (analyzing observations); and communication (relaying information to other machines) [16]. Examples of modern wearable devices include smartwatches (e.g., Apple Watch [17]), wristbands (e.g., Nike Fuelband [18]), intelligent glasses (e.g., Google Glass [19]) and other less common device forms such as the Purple smart locket [20]). To date, relatively little research has been conducted on the design, use and effectiveness of wearables, especially for learning. Arguably, the most common uses of wearables currently is for health purposes, notably fitness trackers that track heart rate and calorie usage (e.g., [21]), and as a proxy to send and receive phone calls and messages.

From responses to an online survey of 66 experts in higher education, Bower and Sturman [22] identified 14 affordances of wearable technologies to support education and learning. They classify the 14 affordances into 3 categories: A. capabilities of wearables that may have pedagogical uses, e.g., providing in-situ contextual information; recording of information; first-person view; B. capabilities of wearables that may enhance educational quality, e.g., enhancing engagement and focus; enhanced sense of presence; and C. capabilities of wearables that may affect logistic and other aspects, e.g., hands-free access; eliminating boundedness to physical spaces. All in all, wearables afford "interactive, communicative and functional capabilities between users, environment, information and digital data in unique ways" [23]. They differ from mobile devices such as smartphones, PDAs, etc. in terms of key characteristics including portability, intrusiveness, screen space, and media capabilities. They are attached to the wearer, and are thus constantly available whenever and wherever needed.

\section{RELATED WORK}

We reviewed the literature that has addressed the use of wearable technologies to support learning. We note that we are not including literature on electronics or microprocessorbased wearable artifacts, such as the LilyPad Arduno [24], that are also sometimes referred to as wearables. We draw out three points of relevance here that helps to situate our work. First, wearables have been proposed to support more often the teacher, rather than the student. De Freitas et al. [25] give three scenarios by which wearables can be used in education: 1) To deliver lecture materials, assignments, and assessments to the learner on the move; 2 ) To encourage collaborative learning and other work without a physical campus; and 3) To facilitate the collection and compilation of 
experience during field trips. Similarly, Llorente and Morant [26] advance new classroom paradigms for the applications of wearables in "presentation slide control and student response monitoring" and "examination and student metric extraction in the lab".

Second, more work on wearables appear to have addressed formal learning environments than informal settings. For example, Park et al. [27] built a wearable platform to track the child's interactions with the physical world to provide "coherent information, which can readily assist the teachers in evaluating and assessing the progress of children's learning process and their social behavior". Scholl, Wille and Laerhoven [28] proposed a wristband combined with Google Glass to support middle school science 'wet labs' by displaying step-by-step lab protocols on the wristband. There have been work in the literature on the more established movement of ubiquitous computing investigating learning experiences in informal contexts, such as Hall and Bannon's [29] work in museums. The use of wearable sensors and RFID-enabled devices has been explored with regard to the physical activity of children (e.g., Consolvo et al. [30], Lee and Drake [31]), and much less with respect to learning of specific content.

And third, the use of wearables to support learning has been closely tied to mostly quantitative data. This may be because wearable and mobile technologies have been often harnessed in the context of the the 'quantified self' (QS) movement. Self-quantification began as a hobbyist activity, defined as a "highly tailored set of data practices that build upon (and are also constrained by) the specifics associated with one's lives and circumstances" [32]. Collected sensor data for instance is then displayed on dashboards or in specific types of data visualizations for the user to consult. Discussing the challenges of and opportunities for integrating self-quantification into the learning sciences, Lee [33] highlights three characteristics of the QS movement: 1) it typically involves continual and longitudinal collection of data; 2) it entails frequent intermediate reviews of data; and 3 ) there is a privileging of unexpected findings in activities.

We did not find up to date research that look empirically at the use of wearables to collect more qualitative data. Although it makes use of mobile technologies instead of wearables per se, one particularly relevant work is that of Pauw et al. [34]. They call their approach 'life-relevant science learning' and designed a mobile social media app, 'ScienceKit', that allows children to "capture moments of interest in their daily lives with multimedia and connect them to science inquiry by making claims, posing questions, and designing experiments". However, their study was conducted with only 7 learners in a summer camp called 'Kitchen Chemistry' focusing on cooking, whereby the children could record moments of interest only during the time that they were in the sessions. Moreover, much of the children's activity during the camp seemed to have been moderated by facilitators. Part of their findings nevertheless are useful for the purpose in our work. They detail three types of learners' experiences through ScienceKit: 1) the use of ScienceKit to mostly engage in pre-planned scientific inquiry. E.g., a child's video entry detailing his thought processes, hypotheses, and observations during an experiment mixing oil and water using eggs as an emulsifier; 2) the use of ScienceKit to connect with peer-groups while engaging in scientific inquiry. E.g., two children recording videos interviewing one another or the facilitator about what they are doing at the moment with brownies and measurement tools; and 3) the use of ScienceKit to move from interest-driven inquiry to more complex academic-like inquiry. E.g., a child initially posting about an observation he made during breakfast: "Some [strawberries] probably got more care than others. Some are bigger than others.", leading him to later review the ingredients lists on labels.

Moving beyond Pauw et al. [34], our work explores the type of science stories that children would capture in-the-wild given the affordances of wearables.

\section{THEORETICAL FOUNDATION}

\section{Learning from Everyday Experiences}

The use of wearables allows for science reflections to be grounded in children's everyday life. Various theoretical paradigms that capture different aspects of the importance of everyday experiences for learning have been proposed. Situated learning theory [35] suggests that learning happens in "authentic contexts: 'ordinary practices of the culture', or "what students face in the real world" [36]. In an ethnographic case study of a female child from $4^{\text {th }}$ to $6^{\text {th }}$ grade, Bricker and Bell [37] detail the situated events related to science in her daily experiences. They conclude that "many of Brenda's school experiences also represented missed opportunities to create linkages to out-of-school practices, which might have deepened and furthered Brenda's interests and expertise development".

In embodied learning, the idea of embodiment entails that "cognitive processes are deeply rooted in the body's interactions with the world" [38]. Learning is not only about symbols and symbol manipulation, but must ground itself in experience [39] in a physical-spatial, temporally dynamic, social-cultural, and affective world [40]. Particularly for children, Hedges [41] advanced that they are natural "life-theorizers" who "develop working theories for making sense of the natural, social, physical, and material worlds".

Contextual learning acknowledges the diversity in students' experiences and background knowledge. New knowledge is constructed from experiences, and each new experience leads either to assimilation or accommodation in the student's mental representations [42]. Within this framework, Bouillion and Gomez [7] have proposed the notion of "connected science" that uses a curricular design grounded in context characterized by 4 features: a 'real world' community-based problem, partnerships of the school with the community or business, problem-based learning, and student-developed products. 


\section{Science Discourse}

In our work, children relate their everyday experiences with science concepts by capturing discourse using wearables. We analyze discourse about science through the lens of the concept of narrative intelligence. Narrative intelligence posits that "we organize our experience and our memory of human happenings mainly in the form of narrative - stories, excuses, myths, reasons for doing and not doing, and so on" [43, 44]. We advance that there is much potential in students understanding science through telling their own stories about the world - hence their 'science stories'. While children may not be able to express science concepts using scientific terms yet, their personal stories may be founded on implicit science understanding and reveal their mental models of the concepts. We note that we adopt a broad perspective on storytelling here as entailing any "structured narration of experience" [45] that detail "human attempts to progress to a solution, clarification or unraveling of an incomplete situation" [46].

Our understanding of science stories is grounded in the Vygotsky's [47] distinctions between two main types of concepts: Spontaneous concepts are formed through a synthesis of direct experiences with the world by engaging in inductive processes, such as "pattern recognition, comparisons made between multiple events, reflection on activities, and the use of analogical reasoning" [48]. While spontaneous concepts rely on one's common-sense and everyday understanding, scientific concepts are handed to a child typically in formal learning environments by teachers and senior students. Beyond concrete phenomena, scientific concepts are the abstracted generalizations that a child learns, for example, the formal definition of a concept from a textbook. The majority of discourse told in the classroom engage the paradigmatic mode of thought, conveying scientific concepts. We hypothesize that science storytelling through wearables is characterized by students telling stories about science in the moment grounded in their concrete daily experiences interacting with the world. Such storytelling may thus add a new dimension to informal science learning, making it more personallyrelevant, contextualized, and interactive.

\section{STUDY DESCRIPTION}

The specific questions that we addressed in our study were: $R Q$ 1: What kinds of science stories do children capture using smartwatches?;

$R Q$ 2: What is the relationship of science stories captured through smartwatches with informal science learning?' and

$R Q$ 3: What is the general experience of children using smartwatches to contemplate science in-the-wild?.

Our study involved 20 child participants ( 12 boys and 8 girls) aged 8 to 11 (mean age $=9.25)$. Their demographics were as follows: White $(85 \%(\mathrm{n}=17)$; Hispanic: $10 \%(\mathrm{n}=2)$; Asian: $5 \%(\mathrm{n}=1)$ For the study, we made use of the Samsung Gear Neo 2, a standard commercially-available smartwatch, synced with a Samsung Galaxy tablet. The smartwatch battery has a run time of continuous use of up to 72 hours. The 'voice memo' app that allows for voice and sound recording was used as a simple means of allowing storytelling on the smartwatch. Figure 1 shows pictures of the watch with the app opened. The voice memo app comes pre-installed on the smartwatch, and allows for recordings of up to 5 mins each. The recordings are transferred automatically to the tablet via bluetooth when the smartwatch is within range.

The participants were recruited through an announcement on the university student, staff and faculty listservs. Children were registered for the study on a first-come, first-served basis upon the return of a signed consent form from their parents. In our study, the smartwatch acts as a lens to view the world through science, i.e., children are told to record only stories related to a science concept. The study took place over three consecutive days as follows:

Day 1: 1. The child arrived at a lab space at a scheduled time after their school time. He/she was given a brief description of the study, and provided minor's assent to participate in the study; 2. The child watched a 5 mins-long video providing basic facts about a science concept (the concept of either friction or gravity was randomly chosen. For friction, aspects such as what is friction, what influences friction, etc. would be covered) suitable for the children's age range and cognitive level. A focus science concept was given to the children to give us a common baseline in analysis when looking for similarities, patterns and differences; 3 . The child filled in a basic demographic questionnaire; 4 . A researcher introduced the smartwatch and explained to the child how to use the voice memo app to do a recording; 5. The child was given some time to practice creating recordings; 6 . When the researcher was confident that the child knew how to use the smartwatch and the voice memo app, the child was instructed on the requirements of the study (he/she has to collect stories related to the science concept over the course of Day 2 and Day 3). The child was told explicitly that there is no right or wrong answer to the science stories that they could collect. $\mathrm{He} / \mathrm{she}$ was then given the smartwatch to take home.

Day 2: The child used the smartwatch to

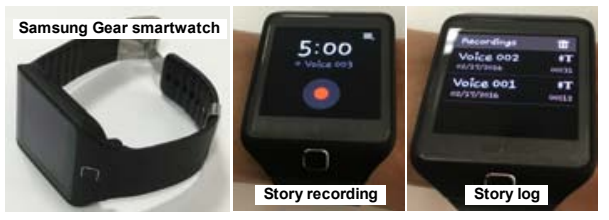

Figure 1. Smartwatch used record stories as he/she saw fit. No interaction between the child and the researcher took place.

Day 3: 1. The child met the researcher at a lab; 2 . The child was interviewed about his /her experience in the study, with the smartwatch, and with storytelling; 3 . The smartwatch was taken back, the child was debriefed;

4) the researcher ensured that the recordings were transferred to the tablet. 


\section{DATA COLLECTION AND ANALYSIS}

A total of seventy-nine smartwatch stories were obtained from the 20 children. All the story recordings were fully transcribed and entered into a spreadsheet for analysis. Basic statistics were first calculated for the stories, including the number of stories per child, and the length of stories per child. A qualitative open coding process was performed by two coders independently on the transcribed stories to identify the (explicit or implied) context in which the story was recorded, the story theme, the type of story, and the role that the child appears to have taken during the recording of the story. The coders also identified how the story addressed the science topic given, i.e., the story's relation to the science concept. The average intercoder reliability for all of these categories was $81.22 \%$. The two coders discussed the cases of disagreement, and agreed on a common code for each case.

We then conducted three further analyses that were based on specific frameworks: first, the stories were coded using the 3 -act story model to determine their narrative structure. The 3 -act model of introduction, middle and end/resolution is the most basic story structure dating back to Aristotle (see [49]); second, Vygotsky's framework (see Theoretical Foundation section) of spontaneous and scientific concepts were used to analyze the stories. All the concepts contained within each story were identified, and then each concept as spontaneous or scientific. For instance, a story excerpt stating "Another force was at work to stop you, friction makes things stop" would be coded as having one scientific concept. Conversely, "Friction let my pencil stop rolling" would be coded as having one everyday concept; and third, the six strands of informal science learning from the key report by the National Research Council [13] (see Context and Motivation section) was used to analyze the stories.

The post-interviews about the children's experience with the smartwatch were audio-recorded. The recordings were fully transcribed, and a qualitative coding process was performed on the transcripts using the MaxQDA software using the following method: descriptive codes were generated. Essentially, each meaningful idea unit is assigned a code describing the idea, or an in-vivo code using the interviewee's own words is assigned if no better code could be generated [50]; the descriptive codes were then grouped into categories, and then into high-level themes.

\section{STUDY FINDINGS}

\section{RQ 1: Kinds of wearable stories}

Basic story profile: Using the smartwatch, an average of 4.45 science stories were recorded per child over two days. The average length of a story was 41.79 words, which amount to about 3 lines of typed text. A child covered an average of 1.15 themes per science story. Most of the stories had a full 3-part narrative structure $(45.6 \%)$, followed by $33.3 \%$ having only 2 parts, $13.3 \%$ having no narrative structure, and $7.8 \%$ having a hybrid overall structure.

Recording contexts: We were able to identify the context of recording for $39.6 \%$ of the science stories. The identified contexts of recording were classified into 4 main categories, shown in Figure 2:

i) At home: $16.5 \%$ of the identified contexts were in the home. Three specific home contexts were seen: a) the living room. Instances of stories were "I found one of my scientific research when Luke was sliding on the maroon leather couch...", "So when I shuffle my feet across the carpet in our living room it creates friction..."; b) the kitchen. Story examples were "So I had an egg on the counter and it started rolling and then it stopped because of friction", "On Saturday uh my mom was cooking and the way that she was cooking our dinner, she was kind of making smoke..."; and c) the backyard. For example, stories were "When I kick my ball in the tall grass of our backyard it did not go very far because there was too much friction...", "I tested out my friction experiment with my soccer ball in the tall grass of my backyard and the ball...there was too much friction...".

ii) At school: $3.3 \%$ of the science stories were taken at school. Two specific school contexts were found: a) the sports field. E.g., "Today on Thursday we are running outside for PE and I noticed that we are running and it was friction..."; and b) the school yard. E.g., "Today what I noticed was that in recess everyone was playing and the balls were dropping, everyone was running and having fun but without even floating...".

iii) In a vehicle: $11 \%$ of the science stories were done in a vehicle, typically a car or a bus, when the child was being transported to school, an activity, etc. Example stories are "I

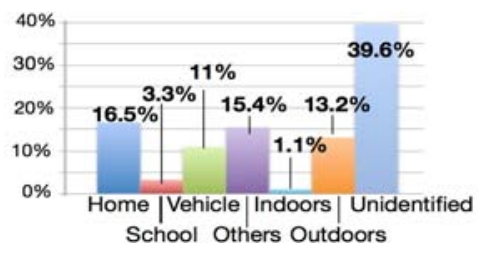

Figure 2. Recording contexts found heard the car rolling around the pavement which counts as friction.", "The bus slowed down to a stop with friction."

iv) Others: Other specific recording contexts were seen to a lesser extent. These included the library (e.g., "The library has a bridge across to it and is being held up by both the library and the walkway across from the other side of it"; at a desk (e.g., "My pencil falls off my desk, my papers fall off my desk, my notebook falls off my desk,..."); at a sports venue (e.g., "When I pivoted on the basketball court I did not slide because I had friction on my shoes."); on the pavement (e.g., I saw a bike that was riding around the pavement which counts as friction."); at a park (e.g., "When I was at the park I was testing out if the bigger rock was going to go down on the ground faster than the little rock..."); on a hill (e.g., "When I was walking up the hill I noticed that it was harder to walk up the hill and that was friction."); and at an afterschool club (e.g., "Today when I was in kids club and...we were doing this thing where there was an experiment about trying to make fake blood out of corn starch and corn syrup, red dye, and blue dye"). 
In the rest of the stories, we were able to identify the recording context as being either outdoors $(13.2 \%)$ or indoors $(1.1 \%)$, but no specific context was identifiable.

Story types: Five story types were found in terms of the form in which children recorded their stories (Figure 3 left):

i) Accounts of personal experiences. These stories (34.78\% of all stories) were about the children relating their current or past designed or ad hoc experience (e.g., "I was sliding my finger on my kindle which makes it friction because I was sliding the finger on the kindle");

2) Observations of happenings. These stories (42.39\%) were about an event that the child observed (e.g., "When my dog rides in the front seat of the car and my mom slams on the brakes his paws have little friction so he flies straight into the window. Poor Shadow.");

3) Narration from a predefined text. These stories (13.04\%) are read from an existing text not original from the child, perhaps from a textbook or a website (e.g., "My third story is about the Triceratops, most common large plant eating dinosaurs of the late Cretaceous period in western North America where the Triceratops, they were found Nowhere else in the world. The word which means horned faced fits with these massive four leg dinosaurs."'); and

4) Working through a thought experiment or a question of interest. In these stories $(9.78 \%)$, the children first pose a question or an issue that they proceed to solve by voicing out their problem-solving steps (e.g., "When I need to move something from one place to another...how could I do it? Well first I could use a piece of wood, put it on there and start dragging it, but that would not work very well because too much friction. But if I use a sled it would be better but still too much friction. Finally, my last option is a wagon which is the greatest one to use because it has wheels which will create the right amount of friction.").

Recording roles: We found that the children adopted 5 main types of roles when recording the smartwatch stories:

i) Observer. This was the most prominent role adopted in $40.2 \%$ of the stories (Figure 3 right). The child analyzes the environment around him/her, and proffers an observation. They adopt an etic perspective, and reflect on something that they saw happen or that was brought to their attention. E.g., "While I'm sitting on the couch I'm noticing my mom's water bottle and it's been sitting out for a while and I'm noticing the condensation on the water bottle because the water has been like evaporating and has been not evaporating condensing on the outside of the water bottle."

ii) Actor. $29.35 \%$ of the stories illustrated this role. The child analyzes his/her own actions that he/she is currently doing, or has recently done either by themselves or with others, and proffers an observation. E.g., "For my first story as we're sitting here playing Mario Cart 8 we're having to use science because we're having to figure out the best combinations of speed, acceleration, handling traction and weight to be the
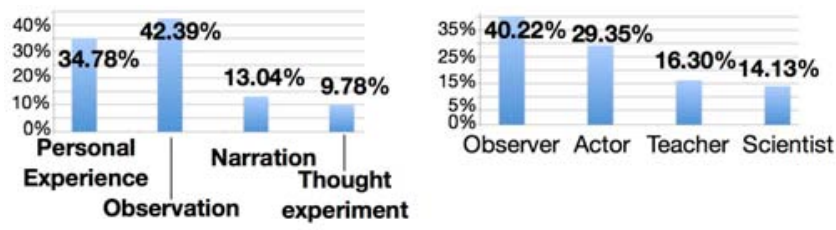

Figure 3. Types of stories recorded (left); Roles children adopted (right)

best or just what we like in a race."

iii) Teacher. We saw this role in $16.3 \%$ of the stories. The child adopts the role of someone tasked to explain a phenomenon akin to an instructor, and explains the subject of the recording in detail as if he/she is teaching someone about the topic. E.g., "If you have gears and they're not running so good if they're not turning right and they won't work, what you do is you get oil and you put it in there so there is less friction so they'll run better but if you don't have oil then there is too much friction and they won't run."

iv) Scientist. In this role $(14.13 \%)$, the child adopts a problem-solving stance toward the world. He/she brainstorms about phenomena, raises questions, and comes up with solutions to the problems that the child either observed or was given. E.g., "If you have a pile of bricks and you're trying to move them from one place to another and you put a piece of wood on the ground and put the bricks on top of that piece of wood and you start to pull or push the wood it wouldn't work because there is too much friction touching the ground from the wood to the ground so what you need is some wheels to put it on there so there is less friction and then you can pull it easier because of the wheels."

v) Hybrid. The roles described are not mutually-exclusive. For instance, children often combined an actor and a scientist role when they conducted self-generated experiments in which they were taking part, but that allowed them to walk through a problem and generate a possible solution. Such a hybrid role is illustrated in the example story: "So what I did was I had my skateboard and I pushed with myself on it, not very fast but it took 9 seconds to go to a full stop. And then I pushed it without me on it and it took ten seconds to stop."

\section{RQ 2: Relationship with science learning}

Vygotsky's framework was used to identify instances of spontaneous and scientific concepts in the children's stories. On average, a story contained 1.59 spontaneous concepts and 0.18 scientific concepts. $89 \%$ of the stories had only spontaneous concepts (e.g. "The socks were smooth and the wood was nice and smooth and there must have been less friction which is why I was gliding easily."). Surprisingly, no stories had only scientific concepts. Children would typically accompany a scientific concept with a spontaneous concept, for example, "If it weren't for friction everyday would be like walking down ice. [spontaneous concept] Friction happens when two surfaces are in contact and are trying to move passed each other, they catch and rub and slow each other down. [scientific concept]". 
Relation to science: We found that the stories related to the science concept in 3 ways:

i) the story emphasizes a characteristic or form related to the concept. $59.3 \%$ of the stories addressed the science concept in that manner. An example would be a story that describes a 'type of friction': "I found one of my scientific research when Luke was sliding on the maroon leather couch it was friction but he glided very easily so I figured the leather couch must have been smooth even though he was a little rough so it must have been an in-between friction. Not a lot but not really a little";

ii) the story describes an aspect of the process of the concept. Only $1.1 \%$ of the story illustrated this approach. For example, the following story describes a process relating to gravity: "If you have a pulley and you are trying to lift something up that's crazy heavy all you need to do is have something heavier than the thing that you are trying to pull up. And once you like your strength so what you do is you pull one end of the rope and what you what it'll do is it'll lift up the other end."; and

iii) the story relates the cause and/or effect of the concept. $39.6 \%$ of the stories were in this category. For example, in the short story "So I was on the trampoline and I went up and gravity forced me down", the child related that the result of gravity was that she was pulled back down.

Goals of informal science learning: Our coding process of the science stories using the six strands of informal science learning as a framework revealed that the children engaged mostly (57.14\% in Figure 4) in Strand 2. They were able to utilize what they know about science and apply it to understand what is around them. Strand 3 was also fairly common (32.97\%). The children "manipulate[d], test[ed], explore[d]... and ma[de] sense of the natural and physical world". Strand 1 ("experience[ing] excitement, interest, and motivation to learn about phenomena in the natural and physical world) was scarcely seen (4.4\%) explicitly in the recordings. We do not believe that this meant that the children were not excited or interested, but rather than they did not capture this metacognitive state verbally.

Moreover, only a few stories (4.4\%) engaged Strand 4, where the children "reflect[ed] on science as a way of knowing". Even fewer stories (1.1\%) discussed the children "partici-

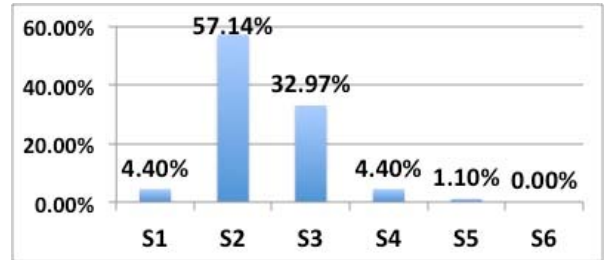

Figure 4. Strands of informal science learning results pat[ing] in scientific activities and learning practices with others" (Strand 5). The most evident one was of a child participating in a science afterschool club. We did not find any instance of Strand 6 ("think about themselves as science learners and develop an identity as someone who knows about, uses, and sometimes contributes to science"). Although the activity of recording science stories in-the-wild may have helped to create a sense of science identity in the child, this was not apparent in the story analysis.

\section{RQ 3: General user experience}

Our coding of the interview transcripts from the children revealed numerous interesting themes with respect to the smartwatch storytelling experience:

A. Device awareness: Many of the children mentioned that they were bothered by others, including their friends and adults, asking about the smartwatch ("it was kind of annoying how many people asked me, is that your watch, why do you have that watch?");

B. Multi-function interface: Other functions of the smartwatch were accessible to the children during the study, although we did not mention any during the study briefing. While the variety of functions led to children accidentally pushing buttons that they did not mean to push, they also keenly explored other watch functions (e.g., steps, timer, stopwatch, music, heart rate, background settings);

C. Appropriateness for in-situ storytelling: There were indications that the smartwatch was suitable for anytime, anywhere storytelling. Particularly, children appreciated that they "can run in it" and that voice recording facilitated their storytelling because they "didn't have to write them down";

D. Perceptions of smartwatch science storytelling: The smartwatch for storytelling seemed to have encouraged reflection in the children on science-related issues, forcing them to figure out what to say ("kind of see what you could say about science like what you did and things"). Example quotes from the children are: "I didn't know that there was science in even more places than I thought that there was" and "science can um you may just look at something and go like oh it's just an object but science is really around you".

\section{DISCUSSION}

We were interested in whether children can use wearables, specifically smartwatches, to view their world and daily embodied experiences through the lens of science anytime, anywhere, and if so, how they would engage in the task. Understanding the types of stories that they capture and how the stories may or may not relate to science informs us on what needs to be paid attention to in the design of wearables apps to support science understanding for children. Wearable technology has opened up a whole new vista of possibilities with regard to informal science learning that was not conceivable with older technology, both in terms of research and practical applications. The higher cost and greater complexity of older technologies (e.g., smartphones, augmented reality, PDAs) has limited many prior studies to controlled settings (i.e., a child using the technology within a (set of) fixed location(s) and within a fixed timeframe), for example, Clegg et al. [51] providing children with tablets when they came in for a summer workshop. 
The smartwatch stories that we obtained from the children were rich and fascinating. The types of stories from the smartwatches were akin to the 'micro-stories' common in microblogging (e.g., Twitter) and Web 2.0., but were slightly longer with somewhat of a narrative structure. The children adopted different roles as they captured science stories. While the data we collected did not allow us to derive any causal explanations for this, one hypothesis to explore would be the differences in personal epistemologies toward science among the children (see [52]) that may link to the types of roles that they adopt for science stories.

We saw that even with basic oral storytelling on the watch, the children began to see that many aspects of their everyday environment relate to science. They recorded science reflections in contexts where they would not have been able to without the watch (e.g., playing outdoors) either because of practical reasons (e.g., with mobile phones), or because they would not have been as 'science-aware'.

From our findings, we outline seven areas that merit much further research for the design of wearables apps that may effectively support children's informal science learning:

1) Encouraging in-situ reflection. Structures are needed in the smartwatch design to encourage scientific reflective acts by children. The task of smartwatch recording by itself was successful in having children take greater notice of their surroundings, as is evident by the high number of stories of the observation type. We were rather dissatisfied however that we did not see deeper or more extensive scientific analysis or inquiry. In the Quantified Self movement, statistics are typically presented on a dashboard that the user consults and reflects on after the fact. A relevant question thus is how may the smartwatch be designed to encourage deeper scientific reflection and inquiry in the moment or immediately after the fact?

2) Maintaining focus on science. In our study of two recording days, simple verbal instructions were sufficient to maintain the child's focus of recording on science. We do not know however whether this focus would endure over a longer study period. A relevant question is what kinds of design features may help to ensure that the scope of recordings are related to a scientific concept of focus?

3) Diversifying contexts of scientific inquiry. The primary contexts of recording were reflective of where children typically spend most of their time, i.e. at home and at school. There were instances of other contexts, but these were not as common as we expected. Looking at varied contexts through the lens of science has the potential to generate much richer understandings in terms of the presence of different artifacts, possible comparisons, etc. A relevant question is how may the smartwatch be designed to enable scientific reflection and inquiry in diversified contexts?

4) Involving others. Our study revealed that wearables are uncommon for children, although the health-focused activity trackers, FitBits, are increasingly seen on children. Adults question the use and appropriateness of wearables for children. The children even found the involvement of others as an intrusion or a "bother". There was a missed opportunity for them to see others as possible participants in their science inquiry. Much of the educational potential identified in microblogging is tied to the social and peer learning opportunities that it provides since all posts are viewable by one's followers [53]. A relevant question is what kinds of structures are needed in the design of a smartwatch to encourage social or collaborative scientific inquiry and discussion in-place?

5) Increasing motivation to record. A child recorded on average around 4 to 5 stories over two days. A challenge of sustained engagement has been noted with smartwatch use [54]. Users typically reported to discontinue use after the novelty factor wears off and the feel of the smartwatch recedes into the background. A relevant question thus is what kinds of motivational design affordances can lead children to use the smartwatch as an educational tool for science learning over long periods of time?

6) Leading to mindset formation. The smartwatch science storytelling task was successful to a certain extent in our study to help the children realize that science is useful in daily life. Nevertheless, the children relied mostly on their existing knowledge of the given scientific concept to observe, analyze and reflect on phenomena. Evidence of the children affirming themselves as a scientist with the possibility of contributing to knowledge was absent. While this may be due to the short duration of our study, a relevant question is how may the smartwatch be designed to encourage children to see themselves as scientists with the ability to contribute new knowledge about the world?

7) Eliminating usability issues. Various issues related to the usability of the smartwatch in terms of learning support were found. Notably, the children were distracted by other smartwatch functions, such as the footstep count, and accidental touches of the smartwatch on the move resulted in unwanted recordings.

\section{CONCLUSION}

We put forth that wearable technologies may enable a new form of informal science learning for children that we have only begun to explore. Our study using the basic audio recording function of a commodity smartwatch provided an initial picture of the kinds of science stories that children may use wearables for, and elucidated the potential of smartwatches to encourage children to see their world through science. It would be interesting to see whether the kinds of science stories that children capture change with the use of more multimedia-based functions. Our study was limited by the sample of students who participated, the short duration of the study, and the design idiosyncrasies of the specific smartwatch that we used. However, our findings allowed us to articulate directions for research in children's wearables for learning that future work may explore by bringing to bear many other relevant areas of HCI, such as critical design, reflective design, notification systems, etc. 


\section{REFERENCES}

[1] Stem Education \& Workforce. (2013). STEM Crisis Page Stats and References. Available: https://nms.org/Portals/0/Docs/STEM Crisis Page Stats and References.pdf

[2] B. D. Jones, "Motivating Students to Engage in Learning: The MUSIC Model of Academic Motivation," International Journal of Teaching and Learning in Higher Education, vol. 21, pp. 272-285, 2009.

[3] National Center for Science and Engineering Statistics, "Elementary and Secondary Mathematics and Science Education," National Science Foundation2014.

[4] M. Andrée, "Ways of using 'Everyday Life'in the science classroom," in Research and the quality of science education, ed: Springer, 2005, pp. 107-116.

[5] K. Mayoh and S. Knutton, "Using out-of-school experience in science lessons: reality or rhetoric?," International Journal of Science Education, vol. 19, pp. 849-867, 1997.

[6] J. Osborne, S. Simon, and S. Collins, "Attitudes towards science: A review of the literature and its implications," International Journal of Science Education, vol. 25, pp. 1049-1079, 2003/09/01 2003.

[7] L. M. Bouillion and L. M. Gomez, "Connecting school and community with science learning: real world problems and school-community partnerships as contextual scaffolds*," Journal of research in science teaching, vol. 38, pp. 878-898, 2001.

[8] S. Hsi, "Technology for Informal and Out-of-School Learning of Science," Encyclopedia of Science Education, pp. 1053-1055, 2015.

[9] H. T. Zimmerman, "Participating in science at home: Recognition work and learning in biology," Journal of Research in Science Teaching, vol. 49, pp. 597630, 2012.

[10] Y. Song, L.-H. Wong, and C.-K. Looi, "Fostering personalized learning in science inquiry supported by mobile technologies," Educational Technology Research and Development, vol. 60, pp. 679-701, 2012.

[11] K. A. Riedinger, "Identity development of middle school students as learners of science at an informal science education camp," 2011.

[12] M. Braund and M. Reiss, "Towards a more authentic science curriculum: The contribution of out-ofschool learning," International Journal of Science Education, vol. 28, pp. 1373-1388, 2006.

[13] P. Bell, B. Lewenstein, A. W. Shouse, and M. A. Feder, Learning science in informal environments: People, places, and pursuits: National Academies Press, 2009.

[14] R. Rawassizadeh, B. A. Price, and M. Petre, "Wearables: has the age of smartwatches finally arrived?," Communications of the ACM, vol. 58, pp. 45-47, 2014.
[15] W. Barfield and T. Caudell, "Basic concepts in wearable computers and augmented reality," Fundamentals of wearable computers and augmented reality, pp. 3-26, 2001.

[16] V. Dibia, "An Affective, Normative and Functional Approach to Designing User Experiences for Wearables," in International Conference on Information Systems SIGHCI 2014 Proceedings, Auckland, New Zealand, 2014.

[17] Apple. (2015, September 20th). Apple Watch: To wear it is to love it. Available: http://www.apple.com/watch/

[18] Nike. (2015, September 20th). Nike+Fuelband.

[19] Google. (2012, September 20th). Glass. Available: https://www.google.com/glass/start/

[20] Startefact. (2015, September 20th). Purple: A locket for the 21st century. Available:

https://www.artefactgroup.com/content/work/purplea-wearable-locket-for-the-21st-century/

[21] C. Boletsis, S. McCallum, and B. F. Landmark, "The Use of Smartwatches for Health Monitoring in Home-Based Dementia Care," in Human Aspects of IT for the Aged Population. Design for Everyday Life, ed: Springer, 2015, pp. 15-26.

[22] M. Bower and D. Sturman, "What are the educational affordances of wearable technologies?," Computers \& Education, vol. 88, pp. 343-353, 2015.

[23] R. E. Gomez, T. Flanagan, and R. M. Davis, "Designing experiences with wearables: A case study exploring the blurring boundaries of art, design, technology, culture and distance," in Proceedings of the 6th IASDR (The International Association of Societies of Design Research Congress), 2015, pp. 805-820.

[24] L. Buechley, M. Eisenberg, J. Catchen, and A. Crockett, "The LilyPad Arduino: using computational textiles to investigate engagement, aesthetics, and diversity in computer science education," in Proceedings of the SIGCHI conference on Human factors in computing systems, 2008, pp. 423-432.

[25] S. De Freitas and M. Levene, "Evaluating the development of wearable devices, personal data assistants and the use of other mobile devices in further and higher education institutions," JISC Technology and Standards Watch Report, pp. 1-21, 2003.

[26] R. Llorente and M. Morant, "Wearable Computers and Big Data: Interaction Paradigms for Knowledge Building in Higher Education," in Innovation and Teaching Technologies, ed: Springer, 2014, pp. 127137.

[27] S. Park, I. Locher, A. Savvides, M. B. Srivastava, A. Chen, R. Muntz, et al., "Design of a wearable sensor badge for smart kindergarten," in Wearable Computers, 2002.(ISWC 2002). Proceedings. Sixth International Symposium on, 2002, pp. 231-238. 
[28] P. M. Scholl, M. Wille, and K. Van Laerhoven, "Wearables in the wet lab: a laboratory system for capturing and guiding experiments," in Proceedings of the 2015 ACM International Joint Conference on Pervasive and Ubiquitous Computing, 2015, pp. 589599.

[29] T. Hall and L. Bannon, "Designing ubiquitous computing to enhance children's learning in museums," Journal of Computer Assisted Learning, vol. 22, pp. 231-243, 2006.

[30] S. Consolvo, K. Everitt, I. Smith, and J. A. Landay, "Design requirements for technologies that encourage physical activity," in Proceedings of the SIGCHI conference on Human Factors in computing systems, 2006, pp. 457-466.

[31] V. R. Lee and J. Drake, "Quantified recess: design of an activity for elementary students involving analyses of their own movement data," in Proceedings of the 12th international conference on interaction design and children, 2013, pp. 273-276.

[32] V. R. Lee, "What's happening in the" Quantified Self" movement?," ICLS 2014 Proceedings, pp. 1032-1036, 2014.

[33] V. Lee, Learning technologies and the body: Integration and implementation in formal and informal learning environments vol. 135: Routledge, 2015.

[34] D. Pauw, T. Clegg, J. Ahn, E. Bonsignore, J. Yip, and J. Uchidiuno, "Navigating connected inquiry learning with ScienceKit," in Eleventh International Conference on Computer Supported Collaborative Learning, Gothenburg, Sweden, June, 2015, pp. 711.

[35] J. Lave and E. Wenger, Situated Learning : Legitimate Peripheral Participation, 1st ed. Cambridge: Cambridge University Press, 1991.

[36] H.-S. Lee and N. Butler, "Making authentic science accessible to students," International Journal of Science Education, vol. 25, pp. 923-948, 2003.

[37] L. A. Bricker and P. Bell, "“What comes to mind when you think of science? The perfumery!": Documenting science-related cultural learning pathways across contexts and timescales," Journal of Research in Science Teaching, vol. 51, pp. 260-285, 2014.

[38] M. Wilson, "Six views of embodied cognition," Psychonomic bulletin \& review, vol. 9, pp. 625-636, 2002.

[39] S. Harnad, "The symbol grounding problem," Physica D: Nonlinear Phenomena, vol. 42, pp. 335346, 1990.

[40] F. Quek, "Embodiment: We're Just Human," in CHI 2011 Workshop on Embodied Interaction: Theory and Practice in HCI, Vancouver, British Columbia, 2011.

[41] H. Hedges, "Vygotsky's phases of everyday concept development and the notion of children's "working theories"," Learning, Culture and Social Interaction, vol. 1, pp. 143-152, 2012.

[42] J. Piaget and B. Inhelder, Memory and intelligence. London: Routledge and Kegan Paul, 1973.

[43] J. Bruner, "The Narrative Construction of Reality," Critical Inquiery, vol. 18, pp. 1-21, 1991.

[44] J. S. Bruner, Actual minds, possible worlds: Harvard University Press, 2009.

[45] R. A. Mar, "The neuropsychology of narrative: Story comprehension, story production and their interrelation," Neuropsychologia, vol. 42, pp. 14141434, 2004.

[46] J. Szurmak and M. Thuna, "Tell me a story: The use of narrative as a tool for instruction," Indianapolis, IN, pp. 546-552, 2013.

[47] L. S. Vygotsky, Ed., Thought and Language, (Edited and translated by E. Hanfmann and G. Vakar) Cambridge: MIT Press, 1987, p.^pp. Pages.

[48] P. Wellings, "Title," unpublished|.

[49] T.-Y. Mou, T.-S. Jeng, and C.-H. Chen, "From storyboard to story: Animation content development," Educational Research and Reviews, vol. 8, p. 1032, 2013.

[50] J. Saldaña, The coding manual for qualitative researchers, 2nd ed.: Sage, 2012.

[51] T. Clegg, E. Bonsignore, J. Yip, H. Gelderblom, A. Kuhn, T. Valenstein, et al., "Technology for promoting scientific practice and personal meaning in life-relevant learning," in Proceedings of the 11th International Conference on Interaction Design and Children, 2012, pp. 152-161.

[52] D. L. Medin and M. Bang, "The cultural side of science communication," Proceedings of the National Academy of Sciences, vol. 111, pp. 1362113626, 2014.

[53] F. Gao, T. Luo, and K. Zhang, "Tweeting for learning: A critical analysis of research on microblogging in education published in 20082011," British Journal of Educational Technology, vol. 43, pp. 783-801, 2012.

[54] V. Dibia. (2015). An Affective, Normative and Functional Approach to Designing User Experiences for Wearables. Available: http://dx.doi.org/10.2139/ssrn.2630715 